\title{
The Response of Patients with Respiratory Failure and Cardiopulmonary Disease to Different Levels of Constant Volume Ventilation *
}

\author{
J. Hedley-Whyte, $\dagger$ H. Pontoppidan, and M. Jocelyn Morris \\ (From the Respiratory Unit and Anesthesia Laboratories of the Harvard Medical School at \\ the Massachusetts General Hospital, Boston, Mass.)
}

The purpose of this study was to determine the effect of increasing the tidal volume on pulmonary ventilation-perfusion relations in patients with respiratory failure caused by cardiopulmonary disease.

The frequent occurrence of an increased physiologic dead space $(2,3)$ and of increased physiologic shunting (3) in patients undergoing prolonged artificial ventilation has previously been described. These changes in ventilation-perfusion ratios mean that very large tidal volumes and high percentages of inspired oxygen are often required to maintain life during prolonged intermittent positive pressure ventilation. The aim of our study was to measure the consequences of changing the tidal volume, but not the respiratory frequency, of patients with respiratory failure secondary to either acute intrapulmonary infection or chronic pulmonary emphysema.

\section{Methods}

Selection of patients. At the time of the study none of the twelve patients had a total vital capacity above 400 $\mathrm{ml}$, and hence all were completely dependent on intermittent positive pressure ventilation. Eight of the patients studied were selected because they had been free of symptomatic pulmonary disease on admission to the hospital, but had later developed nonemphysematous cardiopulmonary disease and acute intrapulmonary infection that caused respiratory failure. The diverse

\footnotetext{
* Submitted for publication January 20, 1966; accepted June 16, 1966.

Supported by U. S. Public Health Service research grants HE 08558-03, HE 06848-05, and HE 09337-01.

Presented in part before the American Society of Anesthesiologists, October 1965. A preliminary report of this work has been published (1).

$\dagger$ Address requests for reprints to Dr. John HedleyWhyte, Massachusetts General Hospital, Boston, Mass. 02114 .
}

nature of the diseases present in these eight patients should be noted (Table I). They have been grouped together for the purpose of contrasting their response to large tidal volumes with the response of emphysematous patients. The other four patients selected had severe generalized pulmonary emphysema. The diagnosis of emphysema (confirmed at autopsy) was made on the following grounds: 1) at least a year's history of unremitting exertional dyspnea, 2) radiological diagnosis of generalized pulmonary emphysema made independently by two radiologists, and 3) a vital capacity between 1.5 and $3 \mathrm{~L}$ and a 1 -second forced expiratory volume less than 700 $\mathrm{ml}$ during tests made more than 6 months before the present studies. None of the patients studied appeared clinically to have intra-alveolar pulmonary edema, nor had any of them had an attack of pulmonary edema in the previous 6 months.

Technique. All patients were supine and horizontal; each had a cuffed tracheostomy tube with an airtight fit in place. Controlled positive pressure ventilation was achieved with a volume constant sinusoid flow generator (Emerson postoperative ventilator) set at a frequency of 20 breaths per minute, inspiration occupying 1 second. The frequency of ventilation was not changed at any time, but tidal volume was changed approximately every 30 minutes. Expiration was passive through a low resistance outlet. Apparatus dead space was measured by water displacement.1 The valve system on each of the two respirators used for all studies was repeatedly checked and found to be competent. For 30 minutes before and during all studies, ventilation was with $100 \%$ oxygen humidified by hot water bypass. Gas analysis and circulatory measurements were made 20 minutes after the change of tidal volume.

Polyethylene catheters were placed percutaneously in either a radial or femoral artery and in the superior vena cava. These catheters were used for blood sampling and continuous pressure recording via a Sanborn 350 system. Continuous intratracheal pressure and the electrocardio-

1 The apparatus dead space, average volume $28 \mathrm{ml}$, extended from the tip of the tracheostomy tube lying in the trachea to the junction of the inspiratory and expiratory tubes of the ventilator, a distance of $25 \mathrm{~cm}$; the internal diameter of the tubing that comprised the apparatus dead space was $1.2 \mathrm{~cm}$. 
TABLE I

Clinical data

\begin{tabular}{|c|c|c|c|c|c|c|c|c|}
\hline \multirow[b]{2}{*}{$\begin{array}{l}\text { Patient } \\
\text { no. }\end{array}$} & \multirow[b]{2}{*}{ Age } & \multirow[b]{2}{*}{ Sex } & \multirow[b]{2}{*}{ Wt } & \multirow[b]{2}{*}{ Diagnosis } & \multirow[b]{2}{*}{$\begin{array}{l}\text { Duration of } \\
\text { artificial } \\
\text { ventilation } \\
\text { before study }\end{array}$} & \multicolumn{3}{|c|}{ Hospital course } \\
\hline & & & & & & $\begin{array}{c}\text { Dis- } \\
\text { charged }\end{array}$ & $\begin{array}{l}\text { Death } \\
\text { (days } \\
\text { after } \\
\text { study) }\end{array}$ & $\begin{array}{l}\quad \text { Death } \\
\text { (chief cause } \\
\text { as determined } \\
\text { post-mortem) }\end{array}$ \\
\hline & years & & $\mathrm{kg}$ & & days & & & \\
\hline 1 & 44 & M & 59 & Pulmonary emphysema. & 4 & & 17 & Emphysema. \\
\hline 2 & 49 & $\mathrm{~F}$ & 42 & $\begin{array}{l}\text { Pulmonary emphysema. } \\
\text { Diverticulitis coli. }\end{array}$ & 7 & & 25 & Emphysema. \\
\hline 3 & 49 & M & 74 & Pulmonary emphysema. & 6 & & 12 & Emphysema. \\
\hline 4 & 72 & $\mathbf{M}$ & 81 & $\begin{array}{l}\text { Pulmonary emphysema. } \\
\text { Postoperative repair } \\
\text { perforated duodenal ulcer. }\end{array}$ & 3 & & 98 & $\begin{array}{l}\text { Myocardial } \\
\text { infarction. } \\
\text { Emphysema. }\end{array}$ \\
\hline $5^{*}$ & 50 & $\mathbf{M}$ & 72 & $\begin{array}{l}\text { Postoperative aortic } \\
\text { mitral and tricuspid } \\
\text { valve replacements. }\end{array}$ & 37 & & 25 & $\begin{array}{l}\text { Partial unseat- } \\
\text { ing tricuspid } \\
\text { valve prosthe- } \\
\text { sis (ventricu- } \\
\text { lar fibrilla- } \\
\text { tion). }\end{array}$ \\
\hline $6^{*}$ & 57 & $\mathrm{~F}$ & 65 & $\begin{array}{l}\text { Postoperative partial } \\
\text { gastrectomy. } \\
\text { Bronchopneumonia. }\end{array}$ & 5 & & 10 & $\begin{array}{l}\text { Cerebral } \\
\text { hemorrhage. } \\
\text { Bronchopneu- } \\
\text { monia. }\end{array}$ \\
\hline $7^{*}$ & 60 & $\mathbf{F}$ & 61 & Viral pneumonia. & 2 & & 12 & $\begin{array}{l}\text { Influenzal } \\
\text { pneumonia. }\end{array}$ \\
\hline $8^{*}$ & 67 & $\mathbf{M}$ & 62 & $\begin{array}{l}\text { Postoperative aortic and } \\
\text { mitral valve replacements. } \\
\text { Bronchopneumonia. }\end{array}$ & 2 & & 19 & $\begin{array}{l}\text { Myocardial } \\
\text { rupture. }\end{array}$ \\
\hline 9 & 50 & M & 85 & $\begin{array}{l}\text { Multiple injuries with } \\
\text { flail chest. Broncho- } \\
\text { pneumonia and aspiration } \\
\text { pneumonitis. }\end{array}$ & 20 & + & & \\
\hline 10 & 17 & $\mathrm{~F}$ & 59 & $\begin{array}{l}\text { Multiple sclerosis. } \\
\text { Bronchopneumonia. }\end{array}$ & 2 & + & & . \\
\hline $11^{*}$ & 70 & $\mathrm{~F}$ & 63 & $\begin{array}{l}\text { Postoperative aortic and } \\
\text { mitral valve replacements. } \\
\text { Bronchopneumonia. }\end{array}$ & 16 & & 17 & Hepatic failure. \\
\hline 12 & 31 & $\mathrm{~F}$ & 45 & $\begin{array}{l}\text { Postoperative aortic and } \\
\text { mitral valve replacements. } \\
\text { Bronchopneumonia. }\end{array}$ & 2 & + & & \\
\hline
\end{tabular}

* No morphologic evidence of pulmonary emphysema was seen on postmortem examination of Patients $5,6,7,8$, or 11 (autopsy no. 28,969, 28,582, 28,595, 28,835, 28,894).

gram (lead 2) were also recorded by this system. Mean pressures were obtained by electrical integration. Immediately before and after arterial sampling, cardiac output was determined by analysis of dye dilution curves with a Gilford $1031 \mathrm{R}$ densitometer. Gas was collected in a 60-L Douglas bag over a period of 3 minutes. Gas volume was measured in a Tissot spirometer, and tidal volume (VT) and minute volume ( $\dot{\mathrm{VE}})$ were calculated. The mixed expired carbon dioxide concentration, $\mathrm{F}_{\overline{\mathrm{E}}} \mathrm{CO}_{2}$, and mixed

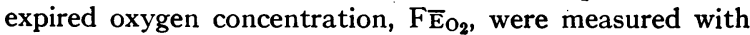
a Beckman model LB-1 infrared carbon dioxide analyzer and a Beckman model E 2 oxygen analyzer, respectively. During the period of gas collection, the arterial and superior vena caval blood samples were slowly withdrawn into $10-\mathrm{ml}$ heparinized glass syringes. Blood carbon dioxide tension was measured with a Severinghaus electrode, $\mathrm{pH}$ by a Radiometer glass electrode, and oxygen tension by a modified Clark electrode with a Sanborn blood gas analysis adapter (model 416-215) and null meter. Blood oxygen content of arterial and superior vena caval blood was measured in duplicate by the techniques of either Van Slyke and Neill or Laver, Murphy, Seifen, and Radford (4). All measurements were required to agree to within $\pm 0.2 \mathrm{vol}$ per $100 \mathrm{ml}$ for any particular sample. Oxygen capacity at $\mathrm{Po}_{2}=150 \mathrm{~mm} \mathrm{Hg}$, temperature $38^{\circ} \mathrm{C}$ (cap), was determined by equilibrating the blood at $38^{\circ} \mathrm{C}$ with a known oxygen tension of between $140 \mathrm{~mm} \mathrm{Hg}$ and $160 \mathrm{~mm}$ $\mathrm{Hg}$ and then measuring the blood oxygen content. All blood gas electrodes were maintained at $38^{\circ} \mathrm{C}$. For patients whose temperature differed from $38^{\circ} \mathrm{C}$, standard blood gas temperature correction factors were applied (5-8). 
The physiologic dead space to tidal volume ratio $(\mathrm{VD} / \mathrm{VT})$ was calculated ${ }^{2}$ as follows:

$$
\mathrm{VD} / \mathrm{VT}=\frac{\mathrm{PaCO}_{2}-\mathrm{P}_{\overline{\mathrm{E}}} \mathrm{CO}_{2}}{\mathrm{PaCO}_{2}}
$$

where $\mathrm{P} \overline{\mathrm{E}}_{\mathrm{CO}_{2}}$ is mixed expired carbon dioxide tension and $\mathrm{PaCO}_{2}$ is arterial carbon dioxide tension.

The physiologic shunt ${ }^{3} \dot{Q} s / \dot{Q}$ was calculated by the standard physiologic shunt equation (11):

$$
Q s / Q=\frac{\mathrm{Cc}_{\mathrm{O}_{2}}-\mathrm{Ca}_{\mathrm{O}_{2}}}{\mathrm{Cc}_{\mathrm{O}_{2}}-\mathrm{Cv}_{\mathrm{O}_{2}}}
$$

where $\mathrm{Cc}_{2}$ is the oxygen content that the patient's arterial blood would have had if equilibrated with mean alveolar gas, $\mathrm{Ca}_{2}$ is arterial oxygen content, and $\mathrm{Cv}_{2}$ is the oxygen content of mixed venous blood. (In this study superior vena caval blood oxygen content substituted for pulmonary arterial blood oxygen content.)

To determine $\mathrm{C}_{\mathrm{O}_{2}}$, we took advantage of the fact that at oxygen tensions of above $150 \mathrm{~mm} \mathrm{Hg}$ hemoglobin is fully saturated (13). Therefore, $\mathrm{Cc}_{\mathrm{O}_{2}}$ was determined by first multiplying the Bunsen solubility coefficient for oxygen in blood by the difference between the oxygen tensions of mean alveolar gas $\left(\mathrm{PAO}_{2}\right)$ and arterial blood $\left(\mathrm{PaO}_{2}\right)$. This multiple was then added to $\mathrm{Ca}_{2}$. (If $\mathrm{Pa}_{2}$ was below $150 \mathrm{~mm} \mathrm{Hg}$, the difference between $\mathrm{PAO}_{2}$ and 150 was multiplied by the Bunsen coefficient and added to the oxygen capacity.)

$$
\mathrm{Cc}_{2}=\mathrm{Ca}_{2}+\left(\mathrm{PAO}_{2}-\mathrm{Pa}_{\mathrm{O}_{2}}\right) \times 0.0031
$$

or if $\mathrm{Pa}_{2}$ was below $150 \mathrm{~mm} \mathrm{Hg}$

$$
\mathrm{Cc}_{2}=\mathrm{cap}+\left(\mathrm{PAO}_{2}-150\right) \times 0.0031 \text {. }
$$

$\mathrm{PAO}_{2}$ was calculated from the simplified alveolar gas equation applicable when nearly pure oxygen has been breathed long enough to allow effective denitrogenation,

$$
\mathrm{PAO}_{2}=\mathrm{PB}-\mathrm{PH}_{2} \mathrm{O}^{\mathrm{T}}-\mathrm{PaCO}_{2} \text {, }
$$

where $\mathrm{PB}$ is barometric pressure and $\mathrm{PH}_{2} \mathrm{O}^{\mathrm{T}}$ is saturated water vapor pressure at the patient's body temperature. ${ }^{4}$

Limitations of method. A detailed estimation of the errors inherent in these methods of calculating the physiologic shunt has recently been presented (14). The use of

2 This equation for VD/VT represents the Enghoff modification of the Bohr equation $(9,10)$. Physiologic dead space as measured by this equation is sometimes called "functional" dead space (10).

a The "physiologic shunt" during pure oxygen breathing measures that proportion of the cardiac output which bypasses functioning alveoli (11). Under these circumstances the physiologic shunt has been called the "true," "pure," or "anatomical" shunt, or the "direct" venous admixture component (12).

4 In the first measurement in Patient 3 and in the first four measurements in Patient 11 (Table III) more than $2 \%$ nitrogen was present in mixed expired gas (due to entrainment of air into the inspired $100 \%$ oxygen), and $\mathrm{P}_{\mathrm{AO}_{2}}$ was assumed to equal $\mathrm{P}_{\mathrm{E}_{2}}+\mathrm{P}_{\mathrm{E}_{\mathrm{CO}_{2}} \text {. }}$ superior vena caval samples to estimate mixed venous blood oxygen content is a compromise dictated by the practicalities of clinical care. In resting normal man, superior vena caval oxygen levels are lower than those of mixed venous blood (15); in anesthetized man during intermittent positive pressure ventilation the average superior vena caval blood oxygen content is $0.25 \mathrm{vol}$ per $100 \mathrm{ml}$ higher than the average mixed venous blood oxygen content (16). In five conscious patients on intermittent positive pressure ventilation after open heart surgery, with peak intratracheal pressures up to levels of $60 \mathrm{~cm} \mathrm{H}_{2} \mathrm{O}$, we found the average superior vena caval blood oxygen content to be 0.3 vol per $100 \mathrm{ml}$ higher than mixed venous blood oxygen content (difference range -0.1 to +0.7 vol per $100 \mathrm{ml}$ ) (17). Thus, in this study, in which intermittent positive pressure ventilation was used, the average error introduced into the calculation of physiologic shunt by using superior vena caval blood samples can be expected to result in an overestimation by $0.5 \%$ of the cardiac output, e.g., a $12 \%$ shunt will be estimated as a $12.5 \%$ shunt.

Statistical methods. In this study a heterogeneous collection of patients was studied. Under these circumstances it is most useful to analyze the results of changing tidal volume by computing the variance in each group of results obtained from each patient being considered and then summing these variances (the numerator of the righthand side of Equation 6 below is these summed variances) (18). These summed variances are then used to get an over-all view of the strength of any relationship in the patients being considered. The within group correlation coefficient $\left(r_{w}\right)$ expresses the strength of this over-all view. Hereafter in this study $r_{w}$ is known as the within patient correlation coefficient, as each "group" of measurements is from one patient. Like the total correlation coefficient $\left(r_{t}\right), r_{w}$ can range only from +1 , perfect positive correlation, to -1 , perfect negative correlation. $r_{w}$ was calculated in the following manner:

$$
\mathrm{r}_{\mathrm{w}}=\frac{\sum_{i=} \sum_{g}\left(X_{i g}-\bar{X}_{\sigma}\right)\left(Y_{i \sigma}-\bar{Y}_{o}\right)}{\sqrt{\sum_{i} \sum_{\sigma}\left(X_{i g}-\bar{X}_{g}\right)^{2} \sum_{i} \sum_{\sigma}\left(Y_{i g}-\bar{Y}_{o}\right)^{2}}}
$$

The total correlation coefficients used to compare data pooled from all patients were calculated as follows:

$$
\mathrm{r}_{t}=\frac{\sum_{i} \sum_{g}\left(X_{i g}-\bar{X}\right)\left(Y_{i g}-\bar{Y}\right)}{\sqrt{\sum_{i} \sum_{g}\left(X_{i g}-\bar{X}\right)^{2} \sum_{i g} \sum_{g}\left(Y_{i g}-\bar{Y}\right)^{2}}} .
$$

In both Equations 6 and 7 the subscript $i$ refers to any measurement (the $i$ th) made in the gth patient; thus $\bar{X}_{\theta}$ is the mean measurement in the gth patient. Significance levels (p) for $\mathrm{r}_{\mathrm{w}}$ were determined taking $\mathrm{n}$ to equal $N-G$ -1 , and for $\mathrm{r}_{\mathrm{t}}$ taking $\mathrm{n}$ to equal $N-2$ in the tables of Fisher and Yates (19) ( $N$ is the total number of observations being considered, and $G$ is the number of patients from whom those observations came).

\section{Results}

Effect of changes in tidal volume on the dead space to tidal volume ratio. The $\mathrm{VD} / \mathrm{VT}$ of pa- 
tients with emphysema ranged from 0.57 to 0.79 ; the $\mathrm{VD} / \mathrm{VT}$ of the remaining patients ranged from 0.38 to 0.75 . In all patients $\mathrm{VD} / \mathrm{VT}$ was almost unaltered by large changes in tidal volume (Figure 1) and cardiac index (Tables II, III). Consequently, since respiratory frequency was constant, physiologic dead space and alveolar ventilation both increased as tidal volume was increased (Figure 1 and Table IV).

Effect of changes in tidal volume on cardiac output. In patients with emphysema increasing the

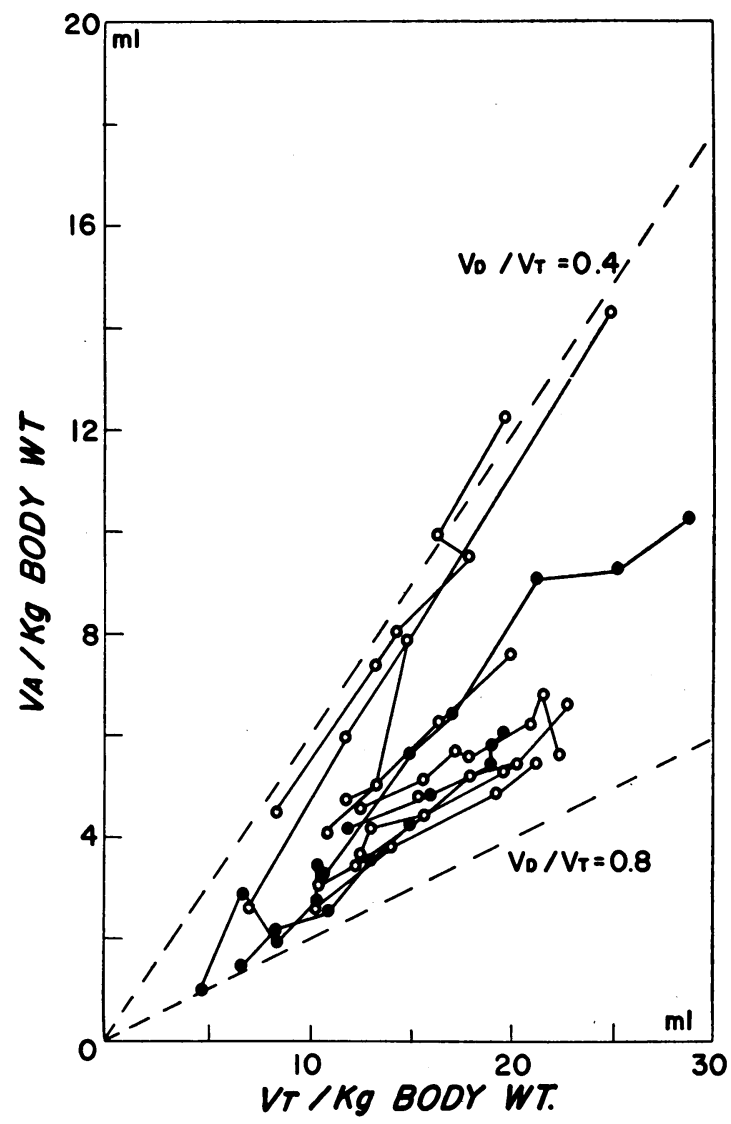

Fig. 1. The relation Between tidal volume and ALVEolar ventilation. With large increases in tidal volume (VT) there was little consistent change in physiologic dead space (VD) to tidal volume ratios. All measurements were made at a respiratory frequency of 20 per minute, inspiration occupying 1 second. Consequently alveolar ventilation (VA) increased in proportion to tidal volume, and most of the plots fall along the $\mathrm{VD} / \mathrm{VT}$ isopleth characteristic of this patient's lung function. Open circles represent measurements in patients with cardiopulmonary disease but without pulmonary emphysema. Solid circles represent measurements from patients with emphysema.

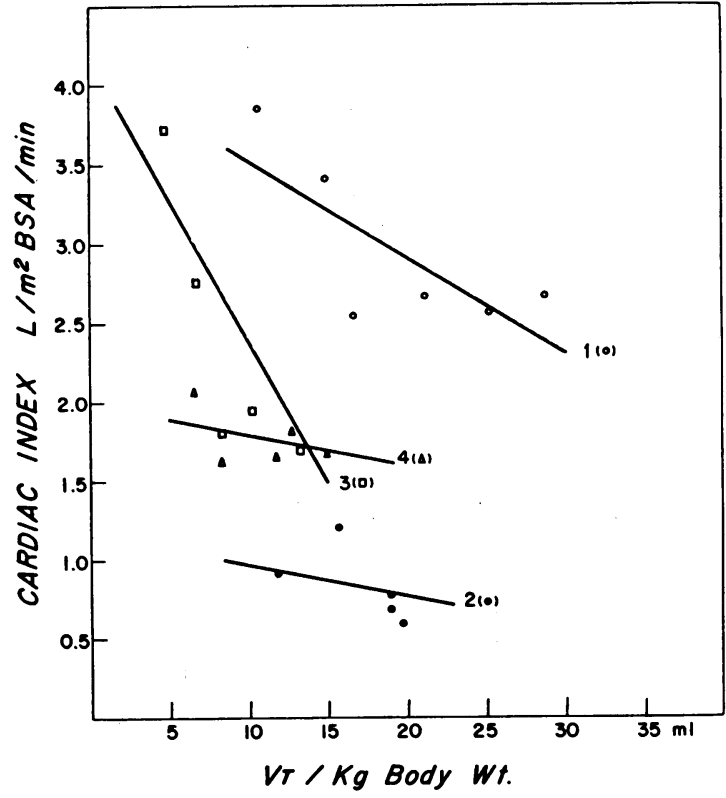

Fig. 2. Tidal volume and CARDIAC INDEX IN EMPHYSEMA. Increased tidal volumes (VT), with respiratory frequency kept constant at 20 per minute, decreased cardiac index in each of four patients with pulmonary emphysema $\left(r_{w}=-0.617, p<0.01\right)$. Linear regression lines are shown for each patient and numbered so that each patient can be identified from Tables I, II, or III. [In patients with nonemphysematous cardiopulmonary disease (not shown), increased tidal volumes did not significantly decrease cardiac output $\left(r_{w}=-0.061\right.$, Table IV)]. $r_{w}$ is the within patient correlation coefficient.

tidal volume decreased the cardiac output (Figure 2) and stroke index (Table IV); however, by contrast, in those patients without emphysema even large increases in tidal volume generally had little effect on the size of the cardiac output or on stroke indexes (Tables II-IV).

Factors affecting the physiologic shunt. The $\dot{Q} \mathrm{~s} / \dot{Q}$ measured during almost pure oxygen breathing ranged from 6 to $79 \%$ of the cardiac output in the patients without emphysema (mean $22.4 \%$ ). Physiologic shunts above $30 \%$ were always associated with dead space to tidal volume ratios of over 0.65 (Figure 3 ). In the patients with emphysema the mean physiologic shunt during almost pure oxygen breathing was $9.1 \%$ (range 3 to $26 \%$ ).

High percentage physiologic shunts occurred at times when cardiac indexes were increased. In each patient there was a positive correlation between cardiac index and the percentage of the cardiac 
PHYSIOLOGIC SHUNT DEAD SPACE AND CARDIAC OUTPUT IN RESPIRATORY FAILURE 1547

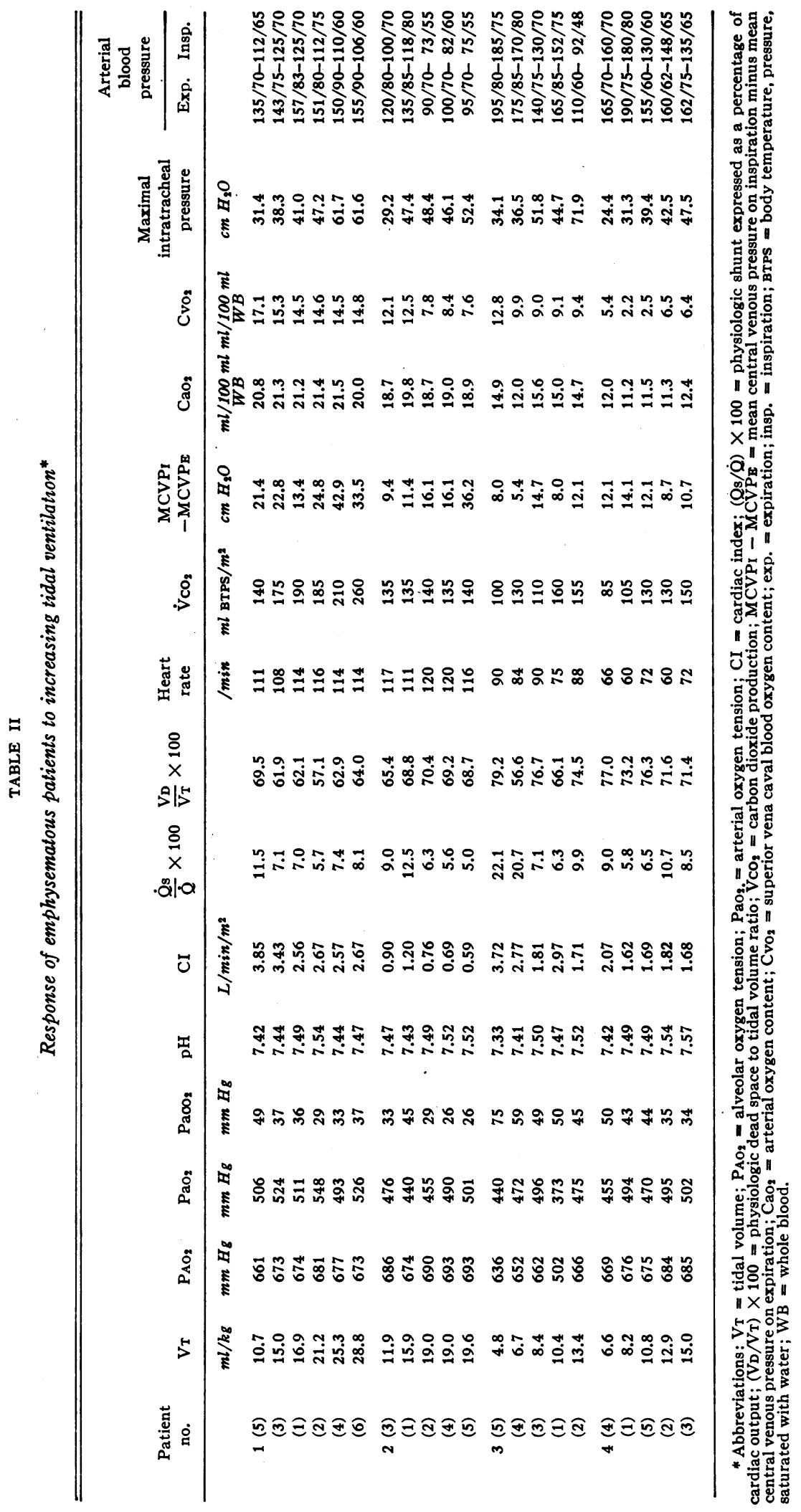


TABLE IV

The effect of changes in tidal volume on respiratory function*

\begin{tabular}{|c|c|c|c|c|c|c|}
\hline \multirow[b]{2}{*}{ Parameters } & \multicolumn{2}{|c|}{$\begin{array}{l}\text { Patients with nonemphy- } \\
\text { sematous cardio- } \\
\text { pulmonary disease }\end{array}$} & \multicolumn{2}{|c|}{ Patients with emphysema } & \multicolumn{2}{|c|}{ All patients } \\
\hline & $\begin{array}{l}\text { Correlation } \\
\text { coefficient }\end{array}$ & Significance & $\begin{array}{l}\text { Correlation } \\
\text { coefficient }\end{array}$ & Significance & $\begin{array}{l}\text { Correlation } \\
\text { coefficient }\end{array}$ & Significance \\
\hline $\begin{array}{l}\text { Cardiac index } \\
\text { Stroke index } \\
\text { Physiologic shunt } Q \text { s/Q } \\
\text { Physiologic dead space } \\
\text { Physiologic dead space to } \\
\text { tidal volume ratio }\end{array}$ & $\begin{array}{r}-0.061 \\
-0.107 \\
-0.275 \\
0.942 \\
-0.278\end{array}$ & $\mathrm{p}<0.001$ & $\begin{array}{r}-0.617 \\
-0.548 \\
-0.369 \\
0.982 \\
-0.130\end{array}$ & $\begin{array}{l}p<0.01 \\
p<0.02 \\
p<0.001\end{array}$ & $\begin{array}{r}-0.251 \\
-0.282 \\
-0.274 \\
0.957 \\
-0.198\end{array}$ & $\mathrm{p}<0.001$ \\
\hline $\begin{array}{l}\text { Mean central venous pressure } \\
\text { Tidal volume/peak intra- } \\
\text { tracheal pressure }\end{array}$ & $\begin{array}{l}0.322 \\
0.637\end{array}$ & $\mathrm{p}<0.001$ & $\begin{array}{l}0.730 \\
0.689\end{array}$ & $\begin{array}{l}\mathrm{p}<0.001 \\
\mathrm{p}<0.01\end{array}$ & $\begin{array}{l}0.496 \\
0.621\end{array}$ & $\begin{array}{l}\mathrm{p}<0.001 \\
\mathrm{p}<0.001\end{array}$ \\
\hline $\begin{array}{l}\text { Mean arterial blood pressure } \\
\text { during inspiration minus } \\
\text { mean arterial blood pressure } \\
\text { during expiration }\end{array}$ & 0.541 & $\mathrm{p}<0.01$ & 0.835 & $\mathrm{p}<0.001$ & 0.669 & $\mathrm{p}<0.001$ \\
\hline
\end{tabular}

* Within patient correlation between tidal volume and parameters concerned in pulmonary ventilation-perfusion relations (respiratory frequency constant at 20 breaths per minute).

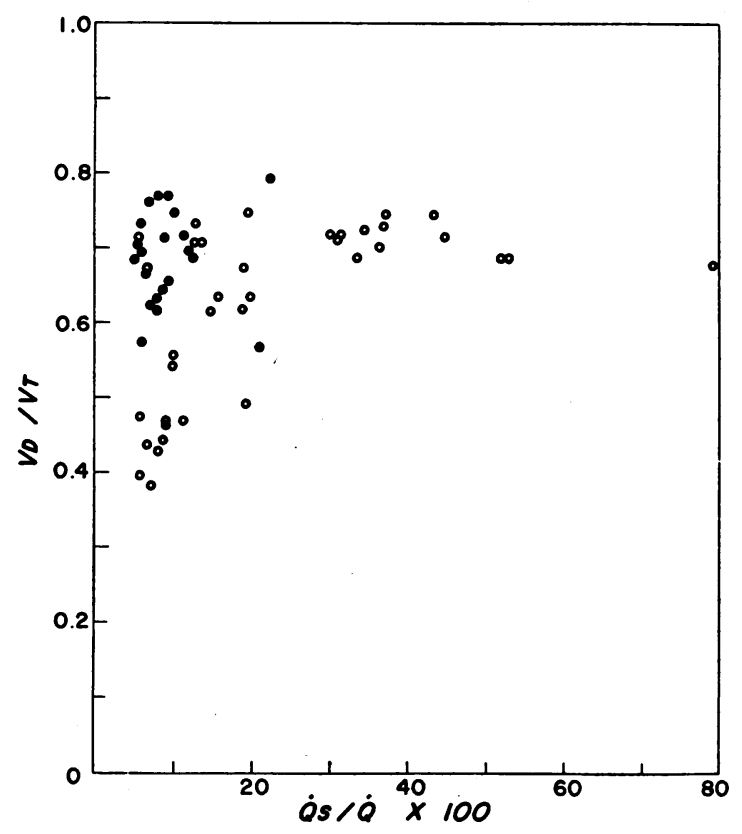

Fig. 3. Physiologic SHUNT AND PHYSIOLOGIC DEAD SPACE. Physiologic shunts (Q்/Q்) of over $30 \%$ of the cardiac output were always associated with dead space to tidal volume ratios $(\mathrm{VD} / \mathrm{VT}$ ) over 0.65 . All measurements were made at a respiratory frequency of 20 per minute. Open circles represent measurements in patients with cardiopulmonary disease but without pulmonary emphysema. Solid circles represent measurements from patients with emphysema. The mean physiologic shunt in patients with emphysema was $9.1 \%$ of the cardiac output; in patients with cardiopulmonary disease but without emphysema it was $22.4 \%$. By contrast, the mean physiologic dead space to tidal volume ratio was similar, 0.673 in patients with emphysema and 0.617 in patients without emphysema. output that was physiologic shunt, the over-all within patient correlation $\left(r_{w}\right)$ being 0.568 ( $p<$ 0.001) (Figure 4).

No significant $(p=0.05)$ within patient correlation was found between the size of the tidal volume and the percentage physiologic shunt.

Effect of changes in tidal volume on peak intratracheal pressure. Ratios of tidal volume to peak intratracheal pressure varied greatly from patient to patient (range 0.0104 to $0.0463 \mathrm{~L}$ per cm water). These ratios were influenced by the size of the tidal volume. The within patient correlation $\left(r_{w}\right)$ between these ratios and tidal volume was 0.689 ( $p<0.01)$ in emphysematous patients, and in patients without emphysema $r_{w}$ was $0.637(p<$ 0.001 ).

When all ratios of tidal volume to peak intratracheal pressure were plotted against VD/VT, the total correlation coefficient $\left(r_{t}\right)$ was -0.257 $(p<0.05)$. Another way of expressing this negative relationship is to say that as tidal volume was increased, peak intratracheal pressure was less in patients with the lower $\mathrm{VD} / \mathrm{VT}_{\mathrm{T}}$ ratios than it was in patients with the higher $\mathrm{VD} / \mathrm{VT}$ ratios. Moreover, changes in $\mathrm{VD} / \mathrm{VT}$, although rarely of great magnitude, were reflected by corresponding changes in tidal volume to peak intratracheal pressure ratios $\left(r_{w}=-0.547, p<0.02\right.$ for emphysematous patients; $r_{w}=-0.513, p<0.01$ for the other patients).

Table IV shows the within patient correlation coefficients $\left(r_{w}\right)$ between tidal volume and the fol- 

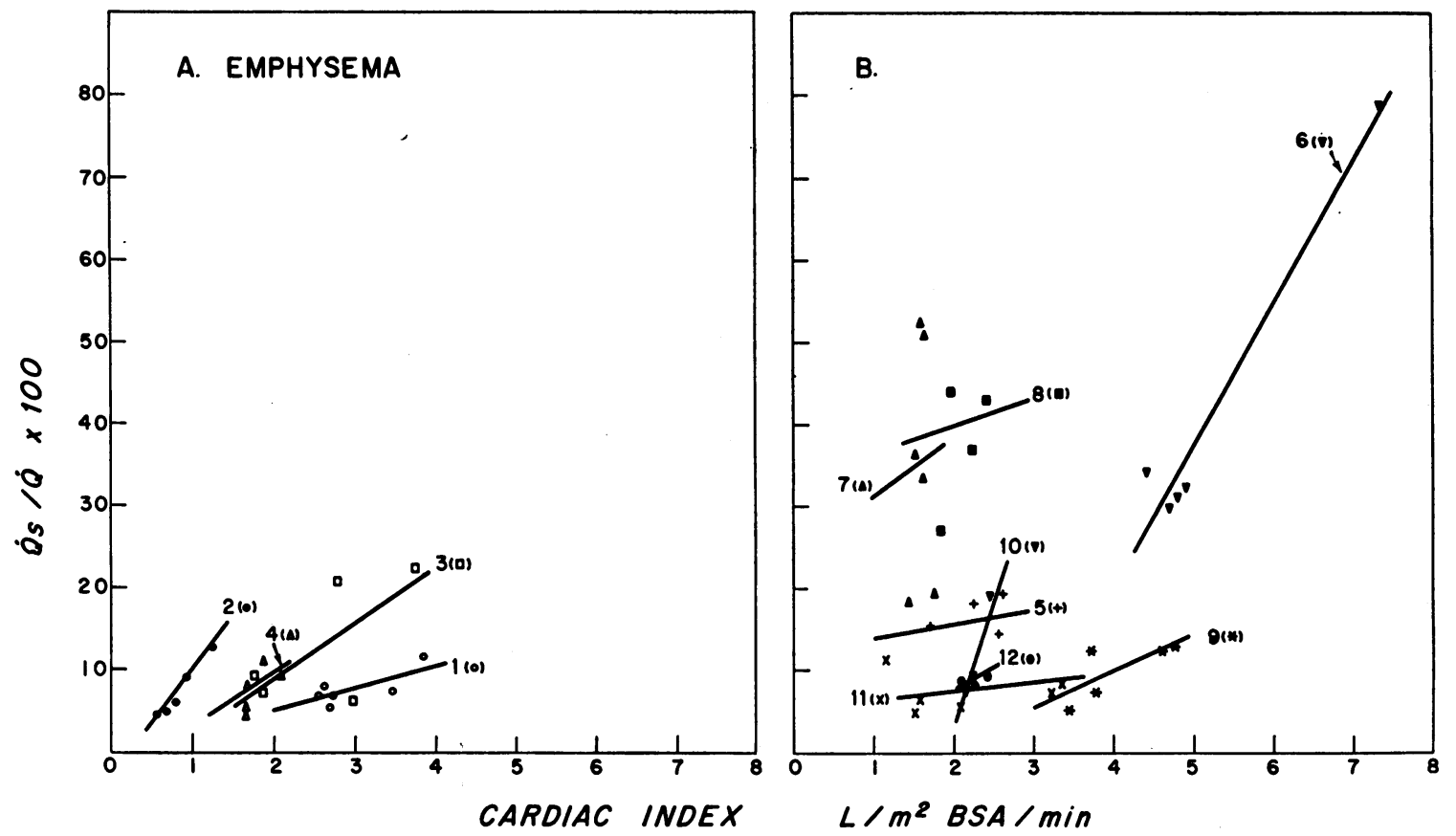

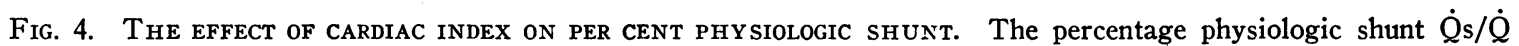
correlated with cardiac index both in patients with pulmonary emphysema (panel $A: r_{w}=0.639, p<0.01$ ) and in patients with cardiopulmonary disease but without emphysema (panel $\mathrm{B}: \mathrm{r}_{\mathrm{w}}=0.581, \mathrm{p}<0.01$ ). Linear regression lines are shown for each patient and numbered so that each patient can be identified from Tables I, II, or III. It should be remembered that each point represents measurements made at different tidal volume (see Discussion) and that the data in these panels are not adjusted for tidal volumes. After adjustments (see Appendix) the two correlations quoted above were changed, $r$ becoming $0.561(\mathrm{p}<0.02)$ in panel A and $0.588(\mathrm{p}<0.001)$ in panel B. It appears, therefore, that the size of the cardiac output is a major determinant of the per cent physiologic shunt. All measurements were made at a respiratory frequency of 20 breaths per minute.

lowing parameters: 1) cardiac index, 2) stroke index, 3) physiologic shunt expressed as a percentage of the cardiac output, 4) physiologic dead space, 5) physiologic dead space to tidal volume ratio, 6) mean central venous pressure, 7) tidal volume to peak intratracheal pressure ratio, and 8) per cent fall in mean arterial blood pressure caused by inspiration.

\section{Discussion}

With respiratory rate constant, the ratio of dead space ventilation to tidal ventilation (ratios ranged from 0.38 to 0.79 ) is almost unaffected by large changes in tidal volume. Cardiac output is greatly decreased by large tidal volumes in patients with emphysema, but generally unchanged in patients without emphysema. The amount of blood flowing through the lungs influences the percentage physiologic shunt. These are the chief findings of this study, and they will be discussed in turn.
Physiologic dead space to tidal volume ratios. In patients with emphysema, and also in severe bronchopneumonia, there is an abnormal distribution of ventilation to alveoli and poor mixing of gases throughout the lung, so that alveolar gas becomes heterogeneous in composition.

Enghoff's modification of Bohr's equation was proposed on the assumption that in normal man, arterial carbon dioxide is in tension equilibrium with the average alveolar carbon dioxide (9); in these circumstances physiologic dead space is equal to anatomic dead space. When extreme unevenness of pulmonary perfusion or ventilation causes a gradient between the arterial carbon dioxide tension and the average alveolar carbon dioxide tension, the physiologic dead space computed by the Enghoff equation will exceed the anatomical dead space, and the difference (alveolar dead space) becomes a measure of the ventilation of relatively poorly perfused alveoli (20). 
The values we have found for physiologic dead space and for the ratio of physiologic dead space to tidal volume are generally higher than other workers (21-24) have found in spontaneously breathing patients. For instance, in the emphysematous patients studied by Donald, Renzetti, Riley, and Cournand, physiologic dead space to tidal volume ratios ranged from 0.29 to 0.59 , and in the patients investigated with interstitial fibrosis or pneumonitis physiologic dead space to tidal volume ratios ranged from 0.21 to 0.67 (21). Similar values have been reported for patients with poliomyelitis ventilated in a tank respirator (2).

In spontaneously breathing normal subjects who hyperventilate, as during exercise, physiologic dead space to tidal volume ratios almost invariably fall (22-24), although total physiologic (but not anatomic) (23) dead space increases. The cause of the increase in the physiologic dead space during voluntary hyperventilation in normal man is controversial. This increase has been explained by Rossier, Bühlmann, and Wiesinger (10) in the following way: "Because of the increased intensity of gas exchange and because of the decreased time allowed for a respiratory cycle, homogeneous gas mixtures no longer exist in the alveoli. Therefore, a somewhat higher carbon dioxide tension exists in the alveolus at the point of gas exchange than is present in the anatomic center of the alveolus." This explanation is not accepted by Bates and Christie (25), who feel that it is unlikely that such an effect could occur in the very small alveoli of normal lungs. This objection does not apply to patients with severe lung disease. Increased heterogeneity of alveolar gas composition within enlarged alveoli is one cause of enlarged physiologic dead space during hyperventilation of patients with lung disease. Since respiratory frequency was constant throughout the study, the larger the tidal volume the higher the inspiratory flow rate. The higher the inspiratory flow rate the greater the proportion of tidal volume distributed to alveoli served by airways with low flow resistances-and the less distribution of ventilation depends on the elastic properties of respiratory pathways (26). The preferential hyperinflation of some alveoli is more marked the higher the tidal volume and will increase intra-alveolar gas heterogeneity and thus calculated physiologic dead space. In emphysema hyperinflation of some alveoli will be aggravated by expiratory check valve mechanisms (27).

In this study, as in a previous study (3), every time the physiologic shunt was in excess of $30 \%$ of the cardiac output, physiologic dead space to tidal volume ratios were in excess of 0.65 . These increases in physiologic dead space are too large to be accounted for by increases in anatomic dead space and must occur chiefly at the alveolar level (20). It should also be noted that apparatus dead space (average $28 \mathrm{ml}$ ) was generally negligible by comparison with physiologic dead space (range 190 to $1,388 \mathrm{ml}$ ).

The effect of tidal volume on cardiac output. Cournand, Motley, Werko, and Richards in 1947 (28) found that a pattern of ventilation, similar to the one used in this study, produced in human subjects ventilated at an average tidal volume of $1.3 \mathrm{~L}$ a mean increase of $6 \%$ in cardiac output. In patients with severe pneumonia and in three patients with severe heart disease, we have found a similar response to large tidal volumes (Table III) in spite of peak airway pressures being on occasion over $100 \mathrm{~cm} \mathrm{H}_{2} \mathrm{O}$-five times higher than in the study of Cournand and co-workers. Possibly the presence of a large physiologic shunt lessens the effect of high intrapulmonary pressure on cardiac output; a sympathetic nervous system response to extreme intrapulmonary distension as well as the provision of normal passive expiration may be added factors maintaining cardiac output in these patients; different degrees of sympathetic response may also explain the great variability of circulatory responses to the start of intermittent positive pressure ventilation.

The different circulatory response to large tidal volumes delivered to patients with emphysema at a constant frequency has important practical implications. In patients with severe lung infections but no emphysema, even extremely large tidal volumes can be employed to maintain an acceptable level of alveolar ventilation. By contrast, in emphysema, if tidal and hence alveolar ventilation is increased with respiratory frequency unaltered, cardiac output may fall to very low levels. If, on the other hand, it is elected to maintain normal tidal volumes (as defined by ventilation nomograms) with high concentrations of oxygen, severe hypercapnia with eventual coma and death may result. 
Factors affecting physiologic shunt. Said and Banerjee (12) found a mean physiologic shunt of $1.7 \%$ of the cardiac output in normal adults spontaneously breathing nearly pure oxygen; by the same methods the mean physiologic shunt in emphysematous patients was found to be $7.4 \%$ (range 2 to 14\%) of the cardiac output. These results are similar to the results we have obtained during the controlled ventilation of emphysematous patients (Table II). In the patients without emphysema, however, the physiologic shunts were generally larger (up to $79 \%$ of the cardiac output, mean 22.4\%). Postmortem findings, although often obtained many days after these studies (Table I), suggest that these large physiologic shunts were caused by perfusion of blood through almost airless lungs.

The amount of blood flowing through the lungs, measured as cardiac output, apparently influenced the distribution of blood within the lungs because the greater the cardiac output the larger was the percentage of blood flowing past unventilated alveoli as physiologic shunt (Figure 4). Similar findings have been reported in spontaneously breathing patients with mitral valvular disease given either isoproterenol or norepinephrine (29). These findings suggest that either the shunt channels in pneumonia, emphysema, or mitral lung disease offer a lower resistance to the increased flow than do the capillaries of ventilated alveoli, or alternatively, that with increasing pulmonary blood flow the critical opening pressure of capillaries in unventilated portions of the lung is suddenly exceeded. A further possibility is that increases in the rate of flow of blood past thickened alveolar membranes mean that insufficient time is available for full saturation of hemoglobin even when nearly pure oxygen is breathed. Such diffusion/perfusion limitations are not evident in normal lungs when cardiac output is changed (30). Moreover, the physiologic shunt in patients with normal lungs is too small (12) for reductions in the percentage physiologic shunt to be easily measurable.

Large tidal volumes in this study did not consistently decrease the percentage physiologic shunt when cardiac output remained constant. This finding contrasts with previous studies ( 31 , 32 ) in which atelectasis of previously normal lungs was produced by an unfavorable pattern of ventilation and subsequently reversed by tidal hyperventilation.

This study, carried out with a ventilator set at a constant frequency, has shown that the greatly increased ventilation requirements of some patients with respiratory failure due to nonemphysematous cardiopulmonary disease can be met by increasing the tidal volume to maintain normal alveolar ventilation. By contrast, in four patients with advanced pulmonary emphysema, and little or no pulmonary infection, large tidal volumes drastically lowered cardiac output.

\section{Summary}

Physiologic dead space to tidal volume ratios from 0.38 to 0.79 and physiologic shunts from 5 to $79 \%$ of the cardiac output were found in patients on long term controlled ventilation. Tidal volume changes at a constant frequency of 20 breaths per minute did not appear to influence the ratio of dead space ventilation to tidal ventilation. This ratio is thus a useful index of cardiopulmonary function during constant frequency controlled ventilation. Tidal hyperventilation decreased the cardiac output in the patients with emphysema, but in the patients with cardiopulmonary disease without emphysema, cardiac output was essentially unaffected by the level of tidal ventilation. The percentage of blood flowing as physiologic shunt was proportional to the cardiac output; therefore, increases in cardiac output were associated with increase in the proportion of the pulmonary blood apparently flowing past unventilated atelectatic, or consolidated, alveoli. In patients with cardiopulmonary disease but without emphysema the level of tidal ventilation did not significantly affect the percentage physiologic shunt. When established lung disease has caused large physiologic shunts and dead space to tidal volume ratios, the distribution of pulmonary blood flow appears to be influenced more by cardiac output than by tidal ventilation and intratracheal pressure.

\section{Appendix}

As noted in the legend to Figure 4, besides within group correlation another technique of variance analysis has been used in this study - the determination of partial correlation coefficients. This technique allowed an assessment of the strength of the relationship between cardiac index and percentage physiologic shunt, having "elimin- 
ated" the effect of the third variable, tidal volume. Since we were considering these three variables, cardiac index, per cent physiologic shunt, and tidal volume, we numbered them 1,2 , and 3 , respectively. There were three within patient correlations among them $r_{w_{12}}, r_{w_{13}}$, and $r_{w_{22}}$. Conceptually, the partial correlation coefficient we were considering was the correlation between variables 1 , cardiac index, and 2, per cent physiologic shunt in a cross section of measurements all having the same value of variable 3 , tidal volume. The over-all within patient partial correlation coefficient $\mathbf{r}_{\mathbf{w 1 2 - 3}}$ was computed by means of the standard formula (33),

$$
r_{w_{12 \cdot 3}}=\frac{r_{w_{12}}-r_{w_{13}} \times r_{w_{23}}}{1-\left(r_{w_{13}}\right)^{2} \times 1-\left(r_{w_{22}}\right)^{2}} .
$$

Significance levels (p) for $\mathbf{r}_{\mathrm{w}_{12 \cdot 3}}$ were determined taking $\mathrm{n}$ to equal $N-G-(m-1)$ in the tables of Fisher and Yates (19) ( $N$ is the total number of observations being considered, $G$ is the number of patients from whom those observations came, and $m(=3)$ is the number of variables considered in calculating $\left.\mathbf{r}_{\mathbf{w 1 2 \cdot 3}}\right)$.

\section{Acknowledgments}

We thank Professor W. G. Cochran of the Department of Statistics, Harvard University, for advice about the statistical analysis of the data. We are grateful to $R$. Castriotta, Miss M. VanDernet, and Miss V. A. Smith for technical assistance.

\section{References}

1. Hedley-Whyte, J., H. Pontoppidan, and M. J. Morris. The relation of alveolar to tidal ventilation during respiratory failure in man. Anesthesiology 1966, $27,218$.

2. Saxton, G. A., Jr., G. E. Rayson, E. Moody, T. McGrath, and J. W. Kaminski. Alveolar-arterial gas tension relationships in acute anterior poliomyelitis. Amer. J. Med. 1961, 30, 871.

3. Pontoppidan, H., J. Hedley-Whyte, H. H. Bendixen, M. B. Laver, and E. P. Radford, Jr. Ventilation and oxygen requirements during prolonged artificial ventilation in patients with respiratory failure. New Engl. J. Med. 1965, 273, 401.

4. Laver, M. B., A. J. Murphy, A. Seifen, and E. P. Radford, Jr. Blood $\mathrm{O}_{2}$ content measurements using the oxygen electrode. J. appl. Physiol. 1965, 20, 1063.

5. Hedley-Whyte, J., E. P. Radford, Jr., and M. B. Laver. Nomogram for temperature correction or electrode calibration during $\mathrm{Po}_{2}$ measurements. J. appl. Physiol. 1965, 20, 785.

6. Nunn, J. F., N. A. Bergman, A. Bunatyan, and A. J. Coleman. Temperature coefficients for $\mathrm{PCO}_{2}$ and $\mathrm{PO}_{2}$ of blood in vitro. J. appl. Physiol. 1965, 20, 23.

7. Bradley, A. F., M. Stupfel, and J. W. Severinghaus. Effect of temperature on $\mathrm{PCO}_{2}$ and $\mathrm{PO}_{2}$ of blood in vitro. J. appl. Physiol. 1956, 9, 201.
8. Adamsons, K., Jr., S. S. Daniel, G. Gandy, and L. S. James. Influence of temperature on blood $\mathrm{pH}$ of the human adult and newborn. J. appl. Physiol. 1964, 19, 897.

9. Enghoff, H. Volumen inefficax: Bemerkungen zur Frage des schädlichen Raumes. Upsala Läk.Fören. Förh. 1938, 44, 191.

10. Rossier, P. H., A. A. Bühlmann, and K. Wiesinger. Physiologie und Pathophysiologie der Atmung, 2nd ed. Göttingen, Springer-Verlag, 1958. English translation, Respiration: Physiologic Principles and Their Clinical Applications. St. Louis, C. V. Mosby, 1960, chap. 1.

11. Berggren, S. M. The oxygen deficit of arterial blood caused by non-ventilating parts of the lung. Acta physiol. scand. 1942, 4 (suppl. 11), 1.

12. Said, S. I., and C. M. Banerjee. Venous admixture to the pulmonary circulation in human subjects breathing 100 per cent oxygen. J. clin. Invest. 1963, 42, 507.

13. Lambertsen, C. J., P. L. Bunce, D. L. Drabkin, and C. F. Schmidt. Relationship of oxygen tension to hemoglobin oxygen saturation in the arterial blood of normal men. J. appl. Physiol. 1952, 4, 873.

14. Hedley-Whyte, J., H. Corning, M. B. Laver, W. G. Austen, and H. H. Bendixen. Pulmonary ventilation-perfusion relations after heart valve replacement or repair in man. J. clin. Invest. 1965, 44, 406.

15. Barratt-Boyes, B. G., and E. H. Wood. The oxygen saturation of blood in the venae cavae, right-heart chambers, and pulmonary vessels of healthy subjects. J. Lab. clin. Med. 1957, 50, 93.

16. Theye, R. A., and G. F. Tuohy. The value of venous oxygen levels during general anesthesia. Anesthesiology 1965, 26, 49.

17. Hedley-Whyte, J., and H. Corning. Unpublished observations.

18. McNemar, Q. Psychological Statistics. New York, John Wiley, 1962, chap. 18.

19. Fisher, R. A., and F. Yates. Statistical Tables for Biological, Agricultural and Medical Research. Edinburgh, Oliver and Boyd, 1963.

20. Severinghaus, J. W., and M. Stupfel. Alveolar dead space as an index of distribution of blood flow in pulmonary capillaries. J. appl. Physiol. 1957, 10, 335.

21. Donald, K. W., A. Renzetti, R. L. Riley, and A. Cournand. Analysis of factors affecting concentrations of oxygen and carbon dioxide in gas and blood of lungs : results. J. appl. Physiol. 1952, 4, 497.

22. Filley, G. F., D. J. MacIntosh, and G. W. Wright. Carbon monoxide uptake and pulmonary diffusing capacity in normal subjects at rest and during exercise. J. clin. Invest. 1954, 33, 530.

23. Wilson, R. H., B. E. Jay, R. S. Meador, and R. Evans. The pulmonary physiologic dead space as an index of effective alveolar perfusion. Amer. J. med. Sci. 1957, 234, 547. 
24. De Coster, A., H. Denolin, and M. Englert. Etude de la ventilation alvéolaire et de l'éspace mort physiologique au repos et à l'effort chez les sujets normaux et pathologiques. Acta med. scand. 1958, $162,47$.

25. Bates, D. V., and R. V. Christie. Respiratory Function in Disease. An Introduction to the Integrated Study of the Lung. Philadelphia, W. B. Saunders, 1964, chap. 2.

26. Mead, J., I. Lindgren, and E. A. Gaensler. The mechanical properties of the lungs in emphysema. J. clin. Invest. 1955, 34, 1005.

27. Neergard, K. von, and K. Wirz. Die Messung der Strömungswiderstände in den Atemwegen des Menschen, insbesondere bei Asthma und Emphysem. Z. klin. Med. 1927, 105, 51.

28. Cournand, A., H. L. Motley, L. Werko, and D. W. Richards, Jr. Physiological studies of the effects of intermittent positive pressure breathing on cardiac output in man. Amer. J. Physiol. 1948, 152,162 .

29. Sanders, C. A., J. W. Harthorne, H. Heitmann, and M. B. Laver. Effect of vasopressor administration on blood gas exchange in mitral disease (abstract). Clin. Res. 1965, 13, 351.

30. Gerst, P. H., C. Rattenborg, and D. A. Holaday. The effects of hemorrhage on pulmonary circulation and respiratory gas exchange. J. clin. Invest. 1959, 38, 524.

31. Hedley-Whyte, J., M. B. Laver, and H. H. Bendixen. Effect of changes in tidal ventilation on physiologic shunting. Amer. J. Physiol. 1964, 206, 891.

32. Hedley-Whyte, J., H. Pontoppidan, M. B. Laver, P. Hallowell, and H. H. Bendixen. Arterial oxygenation during hypothermia. Anesthesiology 1965, 26, 595.

33. Fisher, R. A. Statistical Methods for Research Workers. Edinburgh, Oliver and Boyd, 1954, chap. 6 . 